Chapter 2

\title{
Oral HPV Related Diseases: A Review and an Update
}

\author{
Helena Lucia Barroso dos Reis, \\ Silvia Paula de Oliveira, Danielle Resende Camisasca, \\ Juliana Bittencourt Pessoa, \\ Ana Beatriz Azevedo Queiroz, \\ Mauro Romero Leal Passos, Philippe Godefroy, \\ Dennis de Carvalho Ferreira, \\ Thais Camporez Pimentel and \\ Antonio Chambo Filho
}

Additional information is available at the end of the chapter

\section{Introduction}

Human papilloma virus (HPV) is responsible for the most common sexually transmitted infections. It is estimated that two thirds of people who have unprotected sexual intercourse with a HPV carrier are infected [1].

Since HPV has tropism for epithelial tissue [2-4], it can affect both skin and mucosa [3, 4]. It causes several types of injuries, ranging from asymptomatic infection and benign warts to invasive injuries [5]. HPV infection has been found in a wide range of anatomical sites: genital and anal tract, urethra, upper airway, tracheobronchial mucosa, nasal paranasal cavities, and oral cavity. HPV on oral mucosa presently afflicts $1 \%$ to $43 \%$ of the general population, depending on the diagnosis method used [5], and may be even associated with oral malignancies [6].

The aim of this review article is to offer the academic community an updated review of HPV, emphasizing its importance as a public health matter. This review encloses HPV epidemiology, virology description of different oral lesions, clinical picture, oncogenesis and, diagnostic tools. We have also reviewed current treatment choices and prophylaxis, as well as vaccines against HPV. 


\section{The biology of human papillomavirus - Virion structure}

HPV is a small DNA virus belonging to Papillomaviridae family $[1,2,7,8]$. Its virion consists of a non enveloped, singular double stranded DNA molecule $[5,8,9]$, of about 7.9kb [8], involved by a capsid, of about $55 \mathrm{~nm}$ in diameter [8,9], containing only two structural proteins [8].

HPV genome presents a notable organization. It weighs $5.2 \times 10^{6} \mathrm{D}$ and contains $7.200-8.000$ pairs of nitrogenous bases (pnb) [9]. All putative open reading frames (ORFs) are limited to only one strand of DNA [8]. Non-coding strand probably forms a second, which bears pieces of preserved ORFs, irrespective of localization and composition [8], Chlaudhary et al (2009) have suggested that the basis of the HPV molecule DNA can be divided in three parts. The first part, with $4.000 \mathrm{pnb}$, accounts for viral replication and cell transformation while the second part, with $3.000 \mathrm{pnb}$, represents an important codification zone, since it encodes the viral particle structural proteins. The last one, with only $1.000 \mathrm{pnb}$, contains a non-coding zone; it is, however, fundamental, since the viral origin of replication belongs to this part [9].

\subsection{Genome structure}

The difference of HPV types is due to the variation of E6 and E7 sequence of nitrogenous bases. This variation can produce either an easier to inhibit gene or a harder to inhibit one, thus stratifying the virus oncogenic phenotype into high, intermediate and low risk types [7].Besides its oncogenic potential, the HPV types vary according to tissue tropism and their association with these tissues [10]. Over a $100 \mathrm{HPV}$ types [7] have been identified, but only 25 (HPV - 1, 2, 3, 4, 6, 7, 10, 11, 13, 16, 18, 31, 32, 33, 35, 40, 45, 52, 55, 57, 58, 59, 69, 72, 73) were associated with benign or malignant lesions [3, 10]. Low-risk $\operatorname{HPV}(6,11,38,40,42,54,55,61$, $62,64,67,69,70,71,72,81,83,84,89)$ [11] causes injuries which produce abnormal cell growth [8]; however, they are unlikely to undergo malignant neoplastic transformation. High-risk $\operatorname{HPV}(16,18,26,31,33,35,39,45,51,52,53,56,58,59,66,68,73,82)$ [11] are likely to induce malignant neoplastic transformation $[3,11]$. Recently HPV- 26, 53, 66 have been found to be among the potentially high-risk types [12].

HPV - 6, 11 are related to condyloma acuminatum and, in children, laryngeal papilloma, conjuntival papilloma and genital warts [13]. HPV - 16, 18, mainly, but also 31, 32 and 35 are associated with squamous cell carcinoma [11]. Although benign forms rarely developed into malignant, they can concurrently present with the high-risk malignant injury [9].

\section{Prevalence and incidence}

The American Cancer Society has estimated that more than 6 million people are infected by HPV each year, with 3 million affecting the 15- 25 age group [14].

Asymptomatic oral and oropharynx HPV prevalence at oral cavity has not yet been established [15], probably because different methods were used in different studies [3]. Methods have varied in terms of size of samples, collecting procedures, test sensibility and use of PCR or PCR 
inhibitors. This may explain the huge variation in HPV detection rate: 22 to $60 \%$ or 0 to $81.1 \%$, depending on the methods and on the studied population [15].

Recent meta-analysis has demonstrated that HPV is an isolated risk factor for the development of oral carcinoma [2]. Oral squamous cell carcinoma is known to be linked with both heavy drinking and smoking and it has been related to HPV [6, 7].

\subsection{Oral human papillomavirus infection}

When oral mucosa is considered normal, the epithelium may serve as a container of HPV which would be activated at some point in time and induce injury [16]. A huge number of different oral diseases may be associated with oral HPV, but they rarely cause lesions [17]. Lesions may range from benign warts, which are far more common, to malignant injuries [6].

\subsection{Sexual and nonsexual transmission}

Many studies have discussed HPV transmission, but the mechanisms involved remain unknown. Unprotected sexual intercourse is its leading cause, particularly oral-genital sex, when the genital mucosa is infected by the virus, which will be present both clinically and subclinically $[1,16]$ in adolescent and adults. Early sexual relationships, high number of sexual partners, parity, smoking and another sexually transmitted infection may elevate the rate of virus infection $[6,18,19]$.

Oral HPV can be transmitted by direct skin-skin contact [3] and self-inoculation [1, 4]. Upper airway transmission has not yet been established [8].

Infant HPV is mainly transmitted at birth by infection of the maternal cervix. Thus, the recurrent laryngeal papillomatosis seems to be acquired by such manner [19, 20]. However, another transmission route is mother-fetus, before, during or after the child-birth $[1,4,8]$ that may be made possible by infected amniotic fluid and umbilical cord blood [21].

The transmission of HPV through fomites may also occur [22].

\section{Risk and protective factors}

In the social sphere, people who have yet to initiate sex life have a low probability of HPV infection. On the other hand, people who started their sex life earlier or have a promiscuous sexual life are more likely to have sexually transmitted infections, including HPV. In the economical sphere, it has been found that low levels of HPV infection were strongly related with higher income levels [4].

Early age initial sexual activity, oral sex, more than one sexual partner, not wearing condoms, infrequent use of condoms all pose important risks to any sexually transmitted infection, such as HPV. Homosexuals tend to have greater number of sexual partners than heterosexuals, and as such, they should be more commonly infected than heterosexuals, but studies have yet to confirm this trend $[4,8]$. 
Smoking may pose a lower risk for infection with high risk oral and oropharyngeal HPV than it was previously believed probably because the oral mucosa keratinization makes it stronger against minor traumas and consequently HPV infection. On the other hand, high levels of alcohol consumption have been linked to a higher risk of HPV positivity, but this association needs further research in order to be more fully established [68].

Normally, people acquire HPV during their adolescent years, or when they approach their twenties, when they start their sexual life. An immune competent person can suppress HPV or even eliminate it, and suppressed HPV may be kept subclinical for years [8].

Among the leading protective factors, saliva stands out. It is composed of lysozymes, lactoferrin, IgA and cytokines which seems to be the reason behind low HPV transmission through self-inoculation, oral sex, and the virtually inexistence of transmission through kissing. It has been suggested that regular consumption of carotenoids would contribute to make HPV persistence less likely, and a high consumption of folic acid would reduce the risk of HPV infection [4].

\section{HPV associated oral injuries}

HPV infection range from asymptomatic to visible lesions, which can be benign or malignant [6]. The most common oral manifestations are described below:

\subsection{Condyloma acuminatum}

The lesion is caused by the abnormal proliferation of a squamous stratified epithelium [23]. Formerly it was believed that the only transmission route was by sexual contact, but now it is known that there are other routes, such as self-inoculation and mother-fetus transmission [15]. However, sexual contact remains the main route of transmission (20\%) [23], and people who carry these lesions and practice oral sex have a 50\% chance to acquiring oral condyloma. The incubation period range from 3 weeks to an undetermined period of time; after that, clinic progression will depend on cell permissiveness, virus type and host immune situation [24].

Condyloma acuminatum has tropism to tongue, lips, palate and mouth floor. Clinically, it is described as little pinkish or whitish nodules which proliferate in papillary projections that might be either pedicle or sessile. Outline surfaces present even more evident cauliflower shapes than papilloma, mainly when they converge (Figure 1-A, B).

Histologically, oral condylomata are typically papillary proliferations of squamous epithelium with prominent acanthosis and parakeratin that line deep crypts, similar to their counterparts in the lower genital tract. Koilocytosis is the classic diagnostic feature, consisting of cells with perinuclear halos of various sizes and accompanied by variability in nuclear size and chromaticity, as well as nuclear membrane irregularity. These features are most prominent toward the surface of the lesion (Figure 1 - C, D) [25].

HPV presence was first determined by immunohistochemistry and later by hybridization with 75 to $85 \%$ of positivity [15]. The most involved types are 6 and $11[5,15,18]$. 

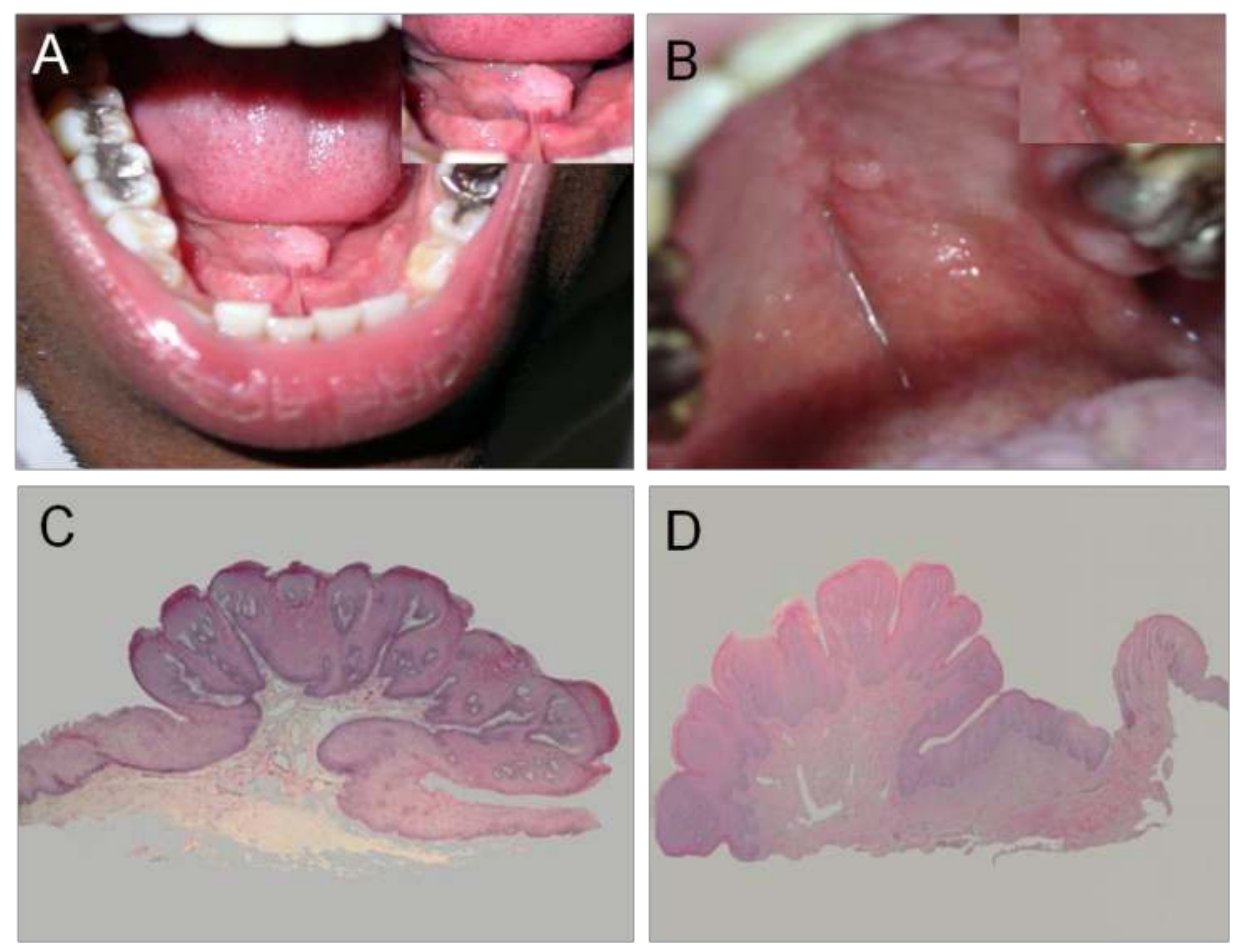

Figure 1. Condyloma acuminatum. Rose-colored nodule with a cauliflower-like surface in the floor of the mouth (A; inset - closer view). Lesion on the hard palate ( $B$; inset - closer view). Microscopically, panoramic view of acanthosis with papillary folds, parakeratosis and elongation of rete ridges (C, D) (HE, Objective 2.5x). Clinical images obtained from the archives of the Stomatology Specialization at Odontoclínica Central do Exército (OCEx).

Differential diagnoses include oral squamous papilloma, verruca vulgaris, molluscum contagiosum, seborrheic keratosis, lichen planus and oral squamous cell carcinoma (OSCC) [15].

Condyloma acuminatum treatment is not always necessary. For 20-30\% of HPV patients, lesions are self-limited and resolve spontaneously within six months, while for $60 \%$ of them, lesions may regress in a year. Relapses affect $20-30 \%$ of patients undergoing treatment, and they may reappear on the same sites or on different locations [24]. The choice of therapy is based on a range of factors, such as lesions size, aspect, number and sites. Other factors of equal significance include patient preference, costs, and adverse effects [23]. Commonly, lesions have been treated by excisional surgery, but in the last years a wider choice of treatments have become available, e.g., cryotherapy, electro cauterization and $\mathrm{CO}_{2}$ laser. Other options include caustic agents, such as trichloroacetic acid, podophyllin and 5-flourouacil which may cause tissue destruction [23]. 


\subsection{Verruca vulgaris (Common wart)}

Verruca vulgaris, also known as common wart is one of the most common lesions affecting mainly children [15], but seldom on oral mucosa [6].

It is usually found on lips, hard palate, gingival, and tongue dorsal surface [15], but especially on lips and tongue [18] (Figure 2 - A, B). Differential diagnoses is made with oral squamous papilloma and condyloma acuminatum $[15,18]$.
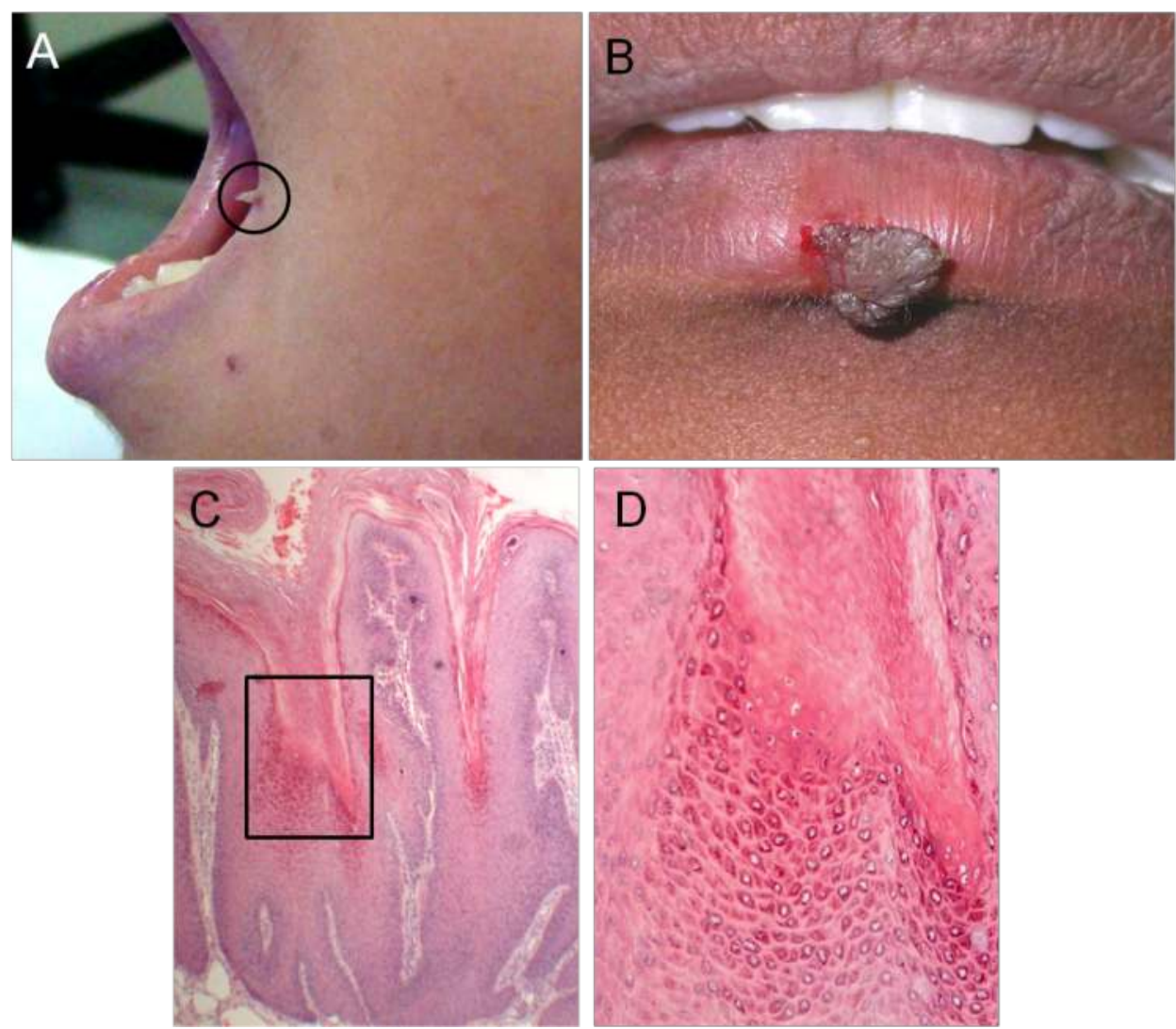

Figure 2. Verruca vulgaris. Exophytic lesion with hyperkeratotic surface, forming finger projections in the left commissure of the lip (A, circle). Lesion on the lower lip (B). Microscopically, panoramic view of acanthosis with papillary folds, hyperortoparakeratosis and elongation of rete ridges (C; HE, Objective 4x). Koilocitosis (D; HE, Objective 20x). Clinical images obtained from the archives of the Stomatology Specialization at Odontoclínica Central do Exército (OCEx).

Histologically, verruca vulgaris show an almost symmetrical structure, with elongated rete ridges that are shorter at the periphery than in central area. Thin elongated connective tissue papillae form papillomatosis. The cryptoform surface shows a conspicuous hyperkeratinization, predominantly composed of orthokeratin. The stratum granulosum is often pronounced, 
particularly in the grooves between the elongated connective tissue papillae. Koilocytes may be seen. In the connective tissue, some dilated capillaries and a slight infiltration with lymphocytes are usually seen (Figure 2 C, D) [26]

Immunohistochemical methods and hybridization tests showed HPV presence in 43 to $100 \%$ of the studied lesions [15].

Most oral warts are self-limited, and resolve within 2 years. Aesthetic discomfort or bite injuries induce patients to look for treatment. Some treatment techniques are cauterization, surgical removal, liquid nitrogen cryotherapy, local hyperthermia, topic 5-fluoracil, $\mathrm{CO}_{2}$ laser, salicylic acid, squaric acid, interferon and wart material implantation [18].

\subsection{Oral squamous papilloma}

Oral squamous papilloma (OSP) is a benign tumor that may occur in all ages, but it more commonly affects adults between 30 and 50 years old [15]. It is mainly related to HPV 6 and $11[15,18]$. In adults, the lesion is usually located in the oral mucosa, mostly on palate and tongue, while in children the laryngotracheobronchial complex is a more common site [27].

OSP affects the soft palate, the lingual frenulum as well as the lower lip [15] and the uvula [27], most often presenting as a single, small lesion smaller than $1 \mathrm{~cm}$, with exophytic growth and a wide basis or pedicle. On histopathology the pattern of epithelial proliferation repeats features described in the previous lesions, with squamous cell acanthosis, hyperkeratosis and a centrally disposed fibrovascular core.(Figure 3 - A, E). Koilocytosis may be present or not.

Oral squamous papilloma may be isolated or multiple-recurring, which is more likely to affect immunosuppressed patients, such as HIV-positive patients. Multiple-recurring papilloma is also more likely to be malignant [27] and tends to relapse more often [28]. Differential diagnoses include exophytic carcinoma, verrucous carcinoma and condyloma acuminatum [27]. Surgical removal is the first choice of treatment, but electrocauterization, cryosurgery and interferon injections are other effective treatment courses [8].

\subsection{Focal epithelial hyperplasia (Heck disease)}

Focal epithelial hyperplasia (FEH) or Heck disease was first described in 1965 [15] and can affect all age groups [29], but it is more common in children and adolescents (3 to 18 years) [30]. Malnutrition, poor hygiene and low social condition as well as genetic background also play an important role [31] in lesion development.

FEH shows a benign epithelial growth and commonly affects oral mucosa, lips, tongue [18], particularly the lower lip and more rarely the palate, floor of the mouth and oropharynx [30]. Clinically it presents as multiple papules $(3-10 \mathrm{~mm})$ [30] that tend to converge. They are characteristically nodular, sessile, circumscribed, painless and soft masses on oral mucosa. Color may range from pale pink to normal mucosa [15, 29-31]. (Figure $4-\mathrm{A}, \mathrm{B}$ ). The diagnosis is both clinical and histological $[30,32]$.

Microscopically it shows epithelial hyperplasia, acanthosis, mild parakeratosis and anastomosing rete ridges. Superficial layers of the epithelial tissue contain cytophatic changes 

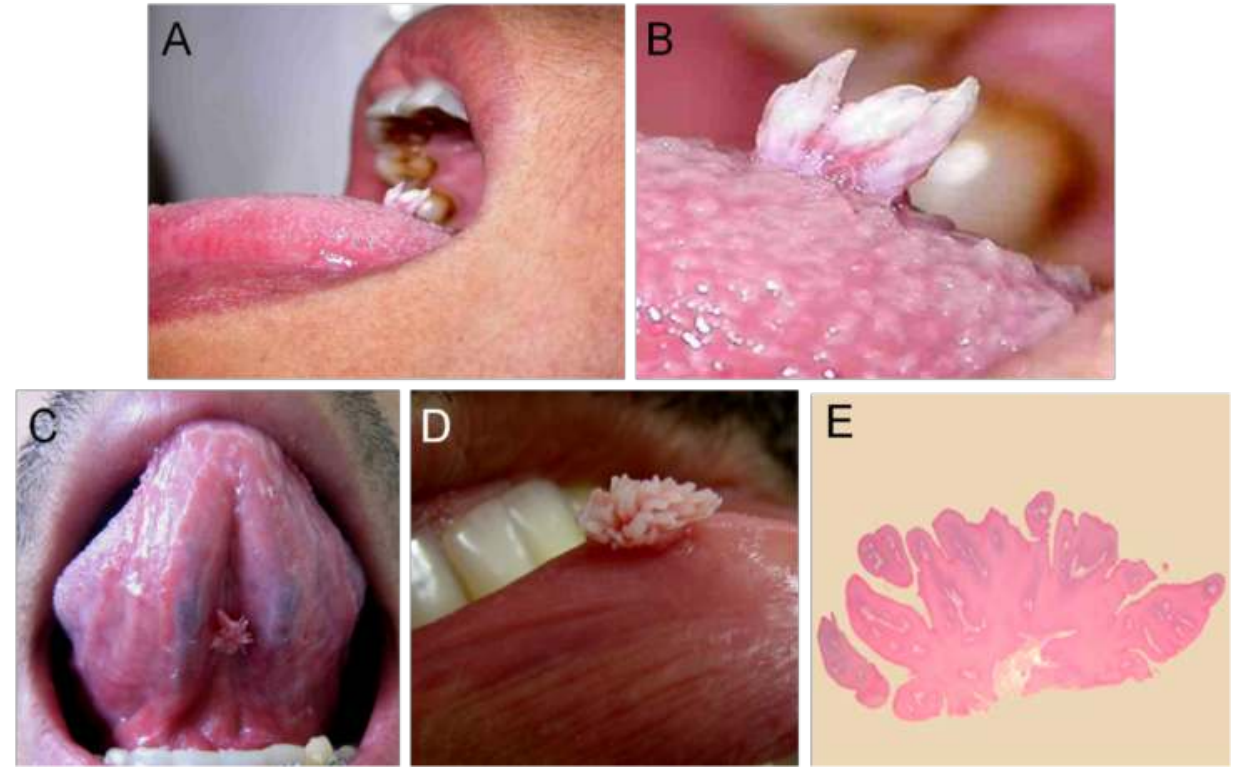

Figure 3. Oral squamous papilloma. Exophytic lesion with hyperkeratotic whitish surface, forming finger projections on the dorsum of the tongue (A-B). Lesion on the inferior surface of the tongue (C). Lesion on the lower lip (D). Microscopically, panoramic view of acanthosis with papillary folds, hyperortoparakeratosis, elongation of rete ridges and a centrally disposed fibrovascular core (E; HE, Objective 2.5x). Clinical images obtained from the archives of the Stomato/ogy Specialization at Odontoclínica Central do Exército (OCEX).

(koilocytosis) and apoptotic or dyskeratotic cells with an apparent mitotic appearance (mitosoid cells) (Figure 4-C, D) [30].

FEH has a steady association with HPV infection, and the most common types are 13 and 32 $[15,29]$; they account for approximately $90 \%$ of infections [30, 32]. HPV-32 might be found in other type of lesions, but never out of the oral region [15]. Both HPV-1 and 11 are rare and show potential for malignancy. So far, the only malignant transformation reported has been found with HPV-24 [32].

Differential diagnoses include condyloma, viral warts, neuroma, white sponge nevus, oral papillomatosis, [30] and inflammatory fibrous hyperplasia.

FEH normally regresses spontaneously in a few months or years, but it can take longer [30]. Thus, treatment is often chosen to mitigate aesthetic problems or repeated bite injuries [31]. The most effective methods are surgical excision, electrocoagulation, cryotherapy [31], $\mathrm{CO}_{2}$ laser and interferon [30].

\subsection{Oral lichen planus}

Oral lichen planus (OLP) is a common chronic immunomediated disease $[18,33,34]$ of unknown etiology seemingly related to HPV in some lesions [18], affecting the skin and the 

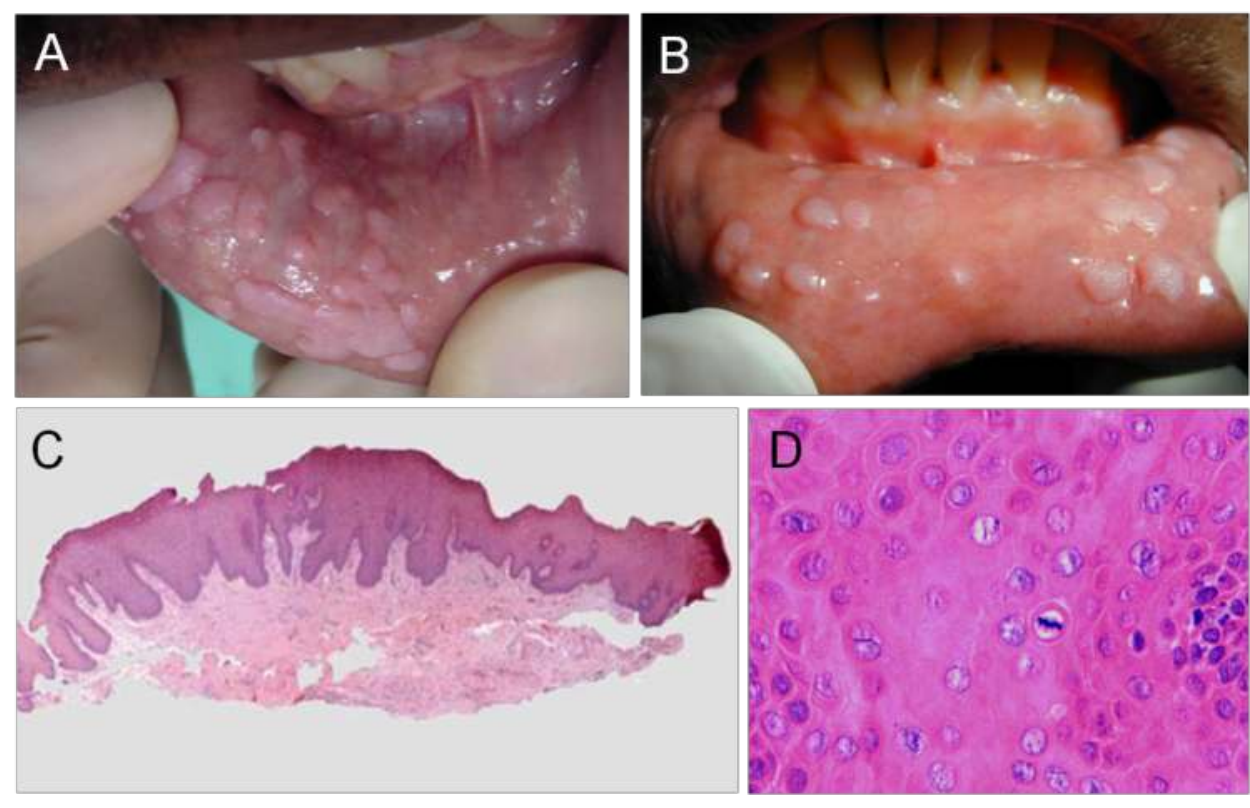

Figure 4. Focal Epithelial Hyperplasia. Multiple flat and coalescent papules on the lower lip mucosa (A-B). Microscopically, panoramic view showing acanthosis and irregular elongation and anastomosis of rete ridges (C; HE, Objective 2.5x). Classic "mitosoid" figure (D; HE, Objective 40x). Clinical images obtained from the archives of the Stomatology Specialization at Odontoclínica Central do Exército (OCEx).

mucosa [33-, 35]. OLP prevalence ranges from $0,5 \%$ to $4 \%$ [35] and mainly affects the female population [33-35]. The most prevalent age is between 30 to 60 years old, although occurrence in children and adolescents seems to be on the rise [35]. In around 15\% of the cases the skin is affected and this number increases to around $85 \%$ of cases affecting the mucosa, particularly the oral and genital mucosa. The oral mucosa is affected in $20 \%$ to $30 \%$ of the cases. Besides being more common, OLP is more resistant to treatment than skin OLP [34]. A possible relationship between OLP to Hepatitis C has been hypothesized, but it has not been clearly established.

Diagnoses depend on clinic manifestation as well as histopathology results [35]. OLP lesions are usually bilateral and symmetric affecting areas the oral mucosa, gingiva as well as the dorsum of the tongue and the lip mucosa (Figure 5-A, F ).

The lesions may be single or multiple and may present in a wide range of forms- cauliflowerlike, striated or annular. Long-time evolution of a lesion is usually atrophic, and when the lesion is located on the tongue it may cause papillae loss and modify gustation (Figure $5-G$, F ). Extensive lesions are also more painful [35]. 

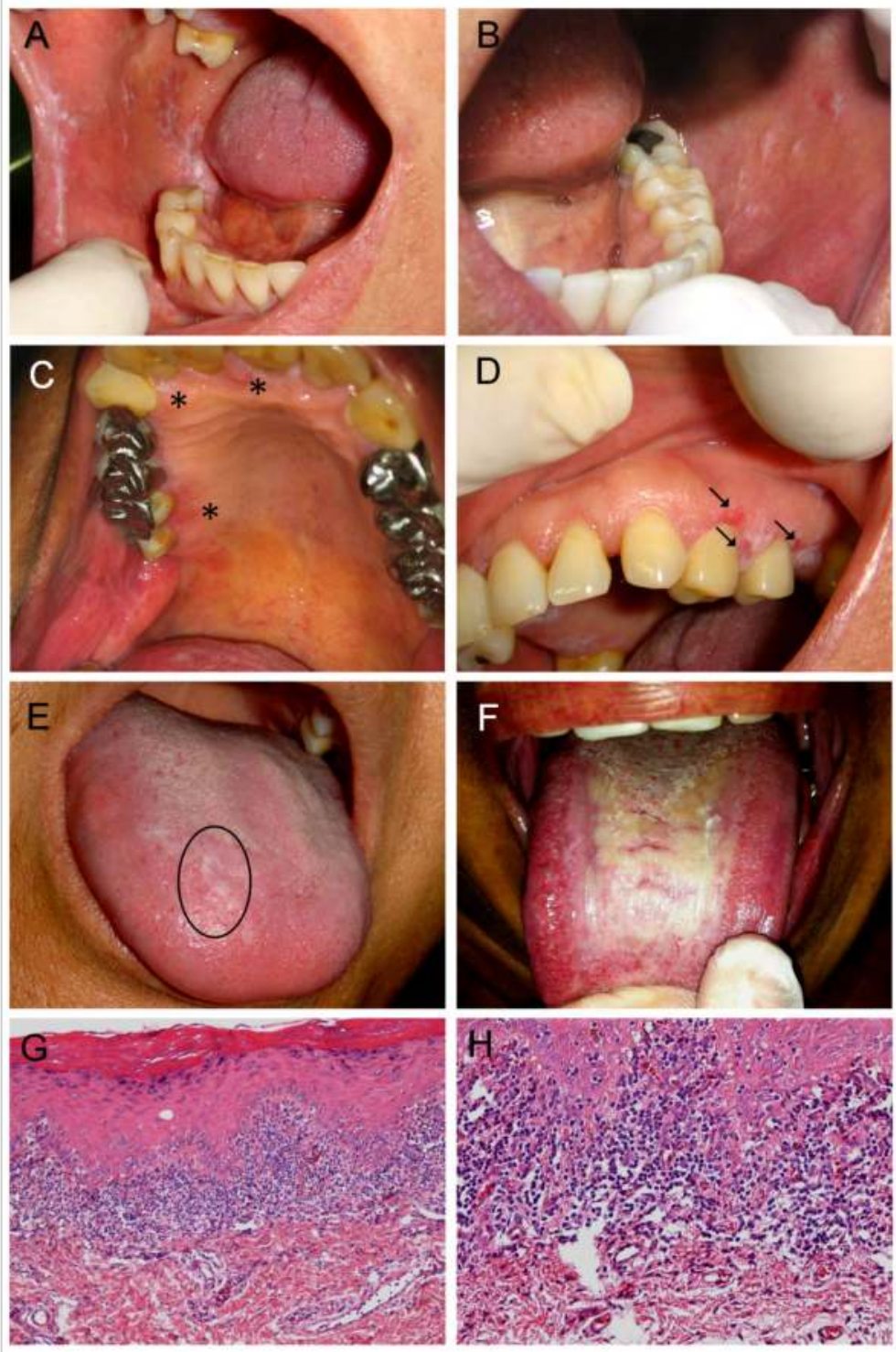

Figure 5. Oral lichen planus. Most prominent features are bilateral white striae in buccal mucosa, with certain symmetry (A-B). Gingiva may also be affected (C-D) $\left({ }^{*}\right)$ and it may show atrophic symptomatic spots surrounded by Wickham striae (arrows). When it affects the tongue, it is not as typical (E-F) and may be confused with oral leukoplakia or smoker's tongue. Microscopically a strong sub epithelial lymphocytic infiltrate should be present (C; HE, Objective 10x), in association with degeneration of the basal layer ( $\mathbf{D} ; \mathrm{HE}$, Objective 20x) and absence of epithelial dysplasia..Clinical images obtained from the archives of the Stomatology Specialization at Odontoclínica Central do Exército (OCEX). 
According to Silverman's classification OLP may be presented as reticular, erosive and atrophic forms [33]. Each form has its different clinic evolution and determines different intensity and duration, with the possibility of evolving from one form into another [35].

On histopathology, we may find acanthosis in keratotic lesions, and atrophy in older lesions. Two important findings are hydropic degeneration of the basal layer, as well as a strong subepithelial lymphocytic infiltrate (Figure $5-\mathrm{G}, \mathrm{H}$ ). Those lesions that present dysplasia should not be classified as OLP [36, 37]. Biopsy should be preferably performed on keratotic areas, however this might be a complicated intervention when the patient has extensive oral candidiasis [34, 35]. Some other pathologic entities may present similar histopathologic features, such as lichenoid reaction, which is similar to lichen planus, but usually is related to amalgam fillings or certain medicines [33, 34].

The most prevalent and commonly found HPV types are 11 and 16 [18].

The conditions that may be considered as differential diagnosis of OLP include the reticular form which should be distinguished from systemic lupus erythematosus, candidiasis, traumatic lesions, secondary syphilis, hairy leukoplakia and incipient OSCC. The erosive form should be distinguished from aphthae, mucous membrane pemphigoid, pemphigus vulgaris, drug reaction, polymorphic erythema and systemic lupus erythematosus acute lesions [35].

Malignant transformation is reported for OLP, however, a current tendency is to consider those lesions that do not fulfill established clinical and pathologic criteria for OLP as oral lichenoid lesions. These lesions mimic OLP and would be the ones truly at risk of becoming a OSCC $[36,37]$.

Treatment does not assure cure, for unknown reasons, but it does reduce symptoms, particular when they are severe, atrophic and widespread. Unlike the asymptomatic reticular form, erosive lesions need prompt symptomatic treatment. Oral hygiene reduces inflammatory lesions and topic corticosteroids may be used in the form of mouth wash. Calcineurin inhibitor, a topic immunosuppressive agent, and topic retinoid, such as imiquimod, are other treatment options, with the latter being used together with topic corticosteroids [33-35].

\subsection{Oral leukoplakia}

Leukoplakia is considered a premalignant lesion or potentially malignant disorder on oral cavity, and reported rates of development into malignancy vary widely depending on the method of diagnosis and definition criteria used for oral leukoplakia [38]. The most common malignant transformation is into oral squamous cell carcinoma (OSCC) [38, 39], with percentages ranging from 3 to $37 \%$ [38].

Oral leukoplakia prevalence ranges from 0,4 to $0,7 \%$, and there is no variability related to gender. However, some researchers believe that prevalence among women is higher [38].

Etiology is uncertain; however smoking along with alcohol consumption is pointed as the main risk factors. There are possible cofactors, such as candidiasis, HPV and more recently EpstainBarr virus (EBV) has been associated with these lesions in imunossupressed patients [38]. EBV 
rarely affects immunocompetent people and it does not need a specific treatment [40]. Treatment should address the underlying cause of immunosuppression.

Oral leukoplakia may be located on lip vermillion, gingival, tongue and floor of mouth, and it is on these latter regions that there is a higher risk of malignancy (around 43\%) [38, 40]. Oral leukoplakia distribution may be local or disseminated [41] (Figure 6-A, F).
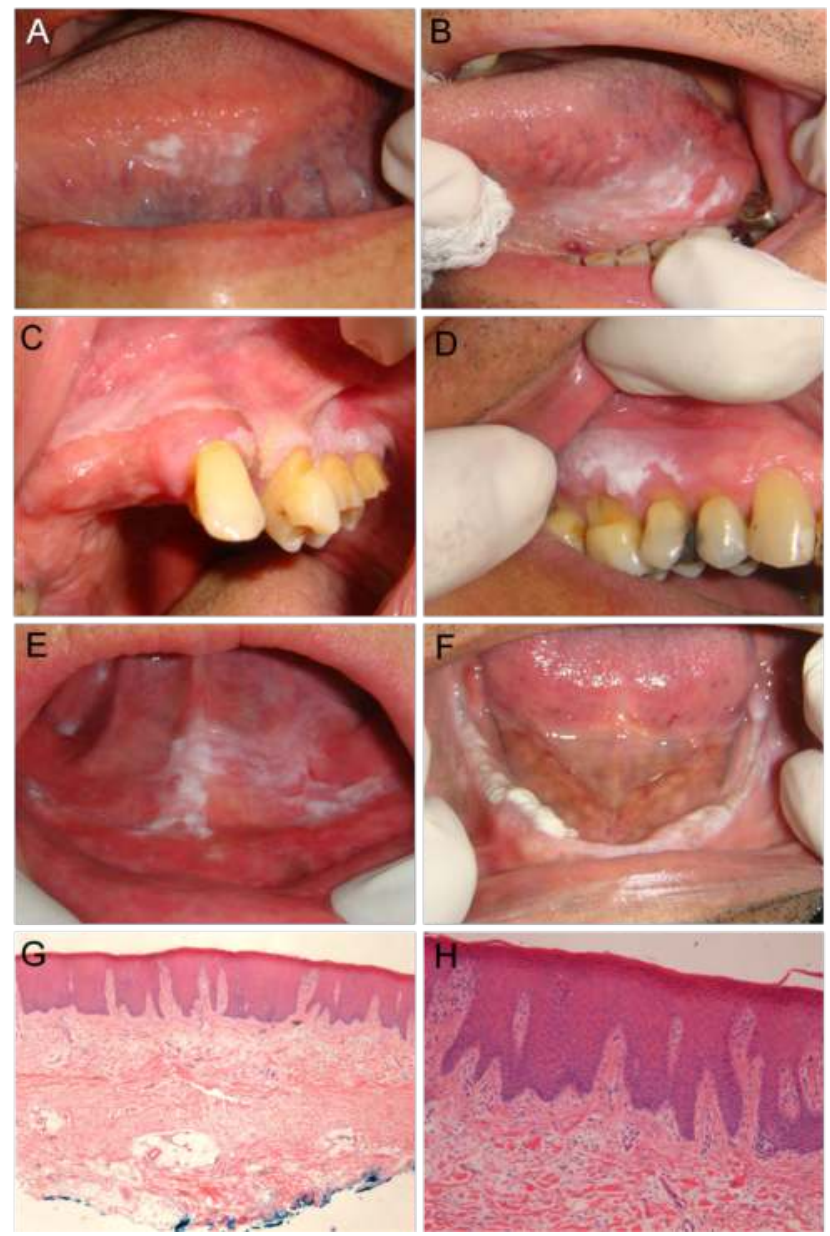

Figure 6. OL: Oral leukoplakia. OL located at lateral (A-B) and ventral tongue show higher risk for malignant transformation. These lesions may be homogenously white (A), or associated with ulcers (B). Other common location is gingiva (C-D), floor of mouth (E) and alveolar ridge (F) and a traumatic cause or association with candidiasis should be ruled out before biopsy. Microscopically leukoplakia can demonstrate only epithelial hyperplasia with acanthosis and hyperparakeratosis (G; HE, Objective 4x), without dysplasia (H; HE, Objective 20x). In this case inflammatory infiltrate was scarce. Clinical images obtained from the archives of the Stomatology Specialization at Odontoclínica Central do Exército (OCEX). 
Histological examination reveals a range of epithelium changes varying from innocuous hyperplasia to dysplasia of varying degrees [18]. However, more commonly, OL presents hyperkeratosis and epithelial hyperplasia without dysplasia [38] (Figure 6- G, H). Depending on the dysplasia degree, it may be classified as low, intermediate and high risk of malignancy [38], so that severity of the dysplasia is the key standard in malignancy prediction [39]. However, diagnosis of dysplasia is rather subjective and as such it is highly dependent on the pathologist/researcher [38,39]. Another controversial issue is that it is virtually impossible to accurately predict which lesion, even among those with dysplasia, will develop into a malignant one [39]. Rather, we might get to know which lesion is more likely to become malignant, if clinic and histological characteristics are analyzed in association [38.37]

Viral etiology is unclear. Although HPV 6, 11 and 16 have been predominantly found, and also HPV 18, 31, 33, $35[18,38]$ in lesions, the viral etiology remains controversial. It seems that lesions which contain HPV are less malignant than oral leukoplakia in smokers, similar to what happens in OSCC. HPV-16 is present in $80 \%$ of the lesions, regardless of malignancy [5], and it has already been established that type 16 is related to OSCC in nonsmoker or nondrinkers. EBV seems to be an etiologic factor of oral leukoplakia because it appears in a great number of malignant lesions in imunossupressed patients [38]

Differential diagnoses are leukoedema, white sponge nevus (Cannon's disease), contact dermatitis lesions, chronic biting, nicotinic stomatitis, OSCC, oral hairy leukoplakia, verrucous carcinoma, OLP and secondary syphilis.

There has not been any agreement as to the best treatment course, and prevention (smoking and drinking avoidance and a diet rich in fruits and vegetables) remains the best approach. A topical treatment based on topical bleomicyn and systemic retinoid is used as an effective short term treatment, however there are doubts as to its long term efficacy. Invasive treatments include cryosurgery, $\mathrm{CO}_{2}$ laser, and surgical resection. They are effective in the short run, but lesions may relapse in the long run $[38,42]$

\subsection{Oral verrucous carcinoma}

Oral verrucous carcinoma (OVC) is a squamous cell carcinoma (SCC) subtype [15, 43, 44], but it shows a much more benign behavior, with well distinguished morphology and clinical presentation. It is located on the head, neck and genitals, and more notably on the oral mucosa, and it has low probability of metastasis $[43,44]$.

OVC is a rare tumor and had been described by Ackerman [15, 43, 44] in 1948 as a cancer that involves the lips, oropharynx and laryngeal mucosa. It is also known as Ackerman's tumor. However, the condition has also been referred as florid oral papilomatosis, epithelioma cuniculatum, carcinoma cuniculatum and also as Buschke-Loewestein tumor [43]. Nowadays carcinoma cuniculatum is considered as a separated pathologic entity [45].

The etiopathogenesis of OVC is unknown, but some studies have found associations mostly with smoking, some alcohol ingestion and infection by HPV [15, 44]. OVC related co-factors are poor oral hygiene, OLP or the presence of leukoplakia lesions. HPV may have an important role in tumor development and progression, but further research is necessary [44]. 
HPV has been widely described as one of the causes of OVC, and the most commonly found types are 6,11,16 and 18, which were identified by polymerase chain reaction (PCR), restriction fragments analyses and DNA slot hybridization [44].

Oral verrucous carcinoma is a male disease and affects predominantly the 50-80 age group [44]. OVC is characteristically situated on the oral mucosa, gingiva, mandible alveolus crest, tongue and lips [44].

It appears with slow exophytic growth, resulting in verrucous cauliflower lesions, with white plaques, normally extensive and with well demarcated hyperkeratotic lesions $[15,43,44]$. It is well circumscribed, invasive only on surface, with low probability of metastasis [43] (Figure7 - A, C). People usually look for doctors because of the extensive rapid growth, which scares them.

OVC histology is characterized by the presence of acanthosis and keratinization with keratin plugging and clefting $[43,44]$. They are irregular and may extend into cleft. Atypia is minimal and usually there is inflammatory infiltrate on the subepthelial layer around epithelial invaginations which seem to compress the underlying tissue ("elephant feet") [44] (Figure $7-\mathrm{D}, \mathrm{E})$.

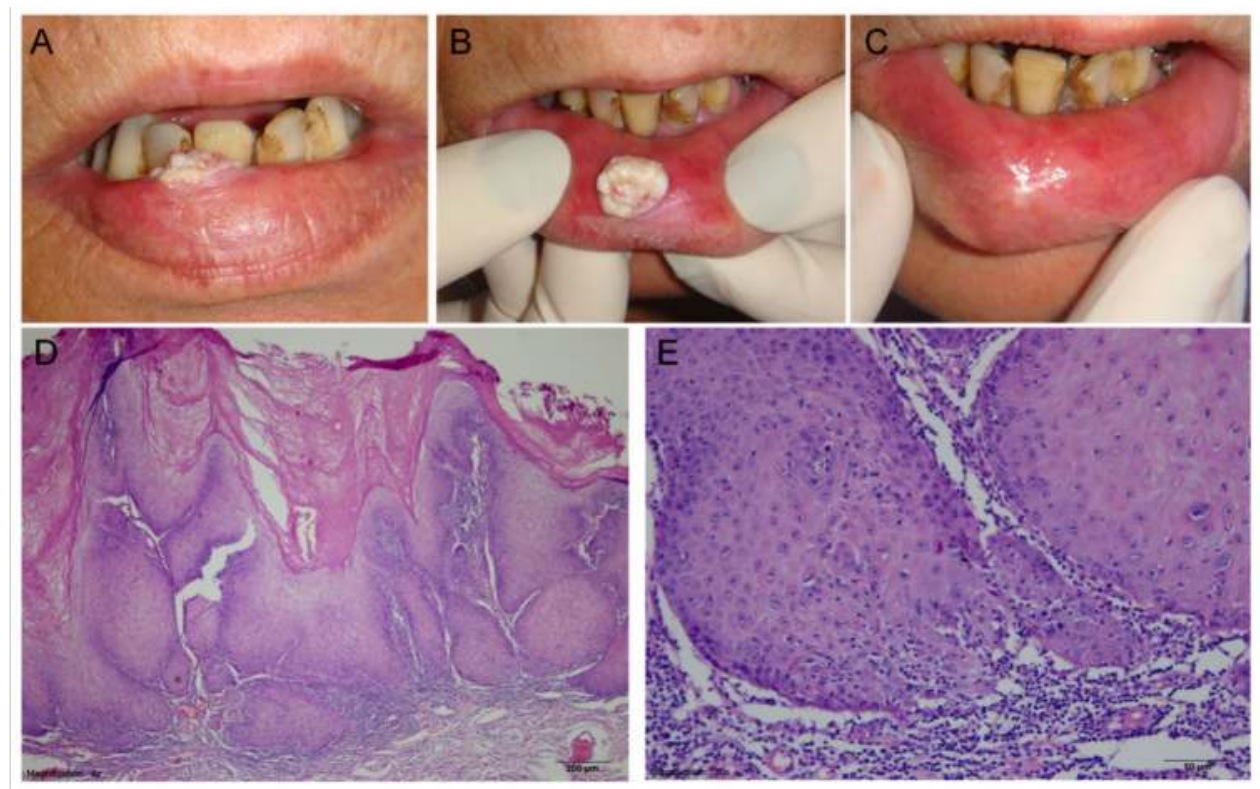

Figure 7. Oral verrucous carcinoma of the lip mucosa. Typical clinical presentation showing an indolor sessile nodule with a white verrucous surface $(\mathbf{A}, \mathbf{B})$. Surgical excision was performed resulting in an excellent esthetic and functional outcome (C). Microscopically, evident hyperkeratosis is observed, with epithelial acanthosis and invasion as pushing borders towards the stroma (D). Minimal epithelial atypia is seen along with a strong lymphocytic infiltrate (E). Images obtained from the archives of the Stomatology Specialization at Odontoclínica Central do Exército (OCEx). 
Main OVC differential diagnosis is verrucous hyperplasia, which is very similar, clinically and histologicallly. Verrucous hyperplasia has in fact been regarded as an OVC precursor [43]. Other differential diagnoses are OLP, benign keratosis, chronic candidiasis, verruca vulgaris, oral leukoplakia, reactive keratosis epithelial hyperplasia, pseudoepitheliomatous hyperplasia. It is difficult to distinguish OSCC from OVC, because they may share a similar clinical picture and incisional biopsy excerpts may not contain atypias [44].

Besides that, tumors mainly composed of OVC may contain small areas of OSCC and behave as one. Ideally, for definitive diagnosis the entire tumor mass with its surrounding tissue should be excised and sent for histopathologic analysis [43].

The treatment main option is surgical resection $[15,46]$ that may be associated with radiotherapy particularly on larger lesions. Relapse rate is high when surgical resection or radiotherapy is performed in isolation. Prognosis of OVC is better than for other types of tumor. Cytostatic drugs, such as $\alpha$-interferon (IFN), should be considered for patients who cannot undergo surgery, but results are not superior from those obtained with surgery [46].

\subsection{Oral Squamous Cell Carcinoma (OSCC)}

OSCC is a worldwide problem [47], representing approximately $3 \%$ of all malignant neoplasms; which means more than five thousand diagnosed cases a day [48], and more than $90 \%$ of all oral cancers [49].

It is a condition primarily related to environmental factors [8] and lifestyle as heavy smoking (more than a pack a day) and drinking (more than 100g a day) [47]. These two are the main risk factors for malignant epithelial transformation. Other risk factors include compromised immune system, poor buccal hygiene and inadequate eating habits [47, 49]. However, OSCC may affect 15 to $20 \%$ of patients with no known risk for the condition [8].

Friedrich et al. reported a $20 \%$ to $30 \%$ HPV association with OSCC [50]. A meta-analysis indicates that oral infection with HPV is an independent risk factor for OSCC. [51] Typically, elderly people $[47,49]$ are more affected than young people. However, the incidence in young adults is increasing. Some studies have shown that OSCC in young adults follow a different clinical course, being more aggressive and affecting more males [47]. On the other side, other authors have shown no difference in survival among elderly and young adults with OSCC [52].

The most commonly affected site for OSCC is the tongue, especially on inferior and lateral surfaces (40\%) [53](Figure $8-\mathrm{A}, \mathrm{F}$ ), but it can also affect buccal mucosa, lips, posterior mandibular ridge, gingiva, hard palate and retromolar trigone [47, 49, 53, 54].

The clinical picture may vary among OSCC types. Typically they are nodular or ulcerative lesions [15, 18], with exophytic or ulceroproliferative features [47]. At more advanced stages lesions present an ulcerated center, not well defined with hard borders. At this point, symptoms such as loss of teeth, bleeding, dysarthria, dysphagia, odynophagia and otalgy may develop [54].Some of them, for unknown reasons, do not progress into metastasis, while others infiltrate quickly, invading the lymph nodes [55]. Tongue and floor of the mouth tumors invade cervical lymph nodes in up to $25 \%$ of initial stage cases $[56,57]$ and are often submitted to 
elective neck dissection. Cervical metastasis at diagnosis is the main indicator of a bad prognosis [45].
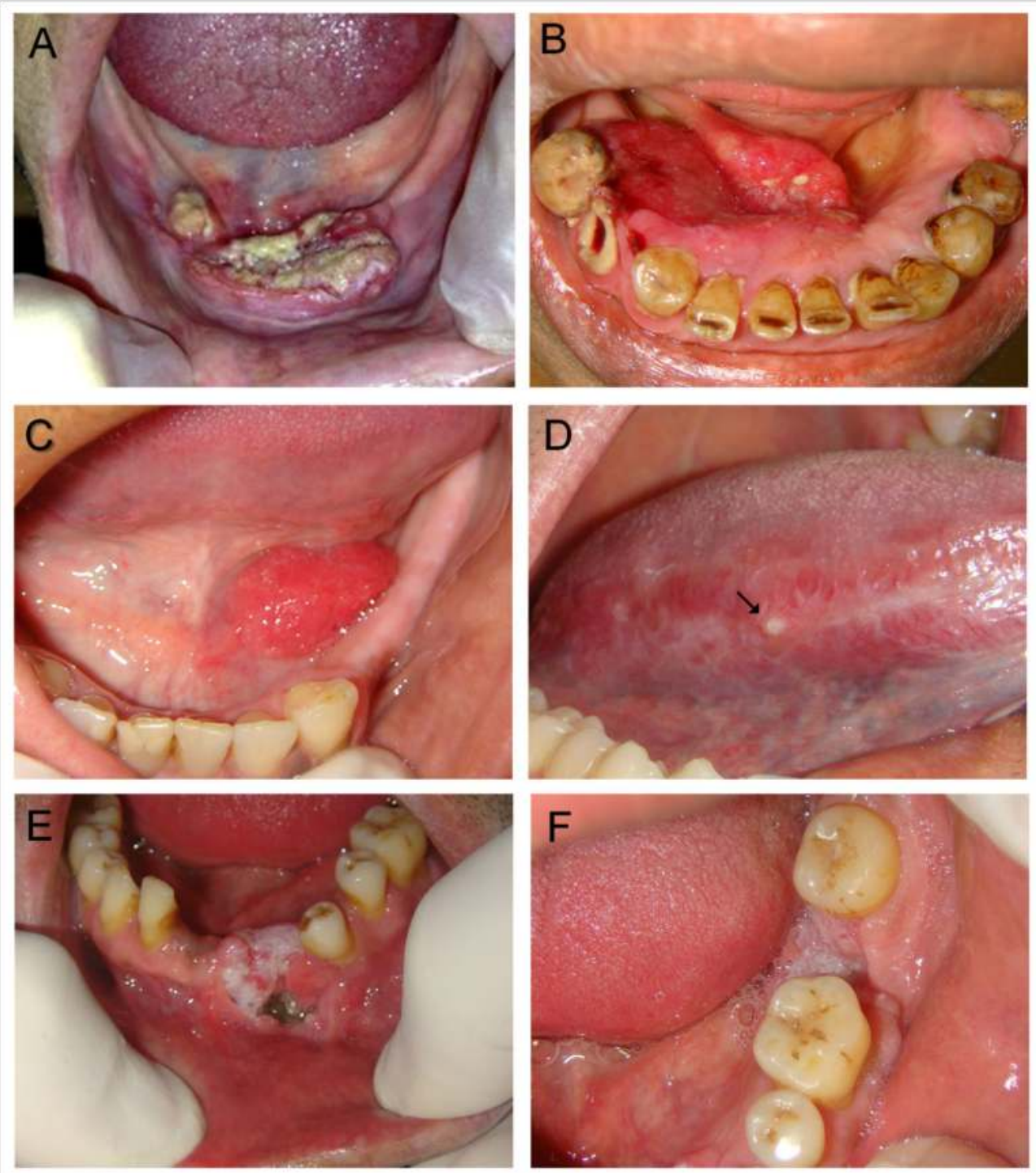

Figure 8. Clinical aspect of OSCC. It may present as an exophityc nodule, ulcerated (A-B) or not (C). It can also be detected as a small induration interspersed in a white plaque (D - arrow). It may show intra osseous invasion (E), with a strong white component, and reach distant sites (F) from the initial spot. Images obtained from the archives of the Stomatology Specialization at Odontoclínica Central do Exército (OCEx). 
Histologically a range of features may be present, but it is important to detect epithelial invasion in the stroma, that may occur as islands, cords, sheets and isolated epithelial malignant cells. Keratin may be present, mostly in well and moderately differentiated tumors. There are varying degrees of atypia, nuclear and cellular pleomorphism with aberrant and regular mitosis (Figure 9 - A, D). Usually poorly differentiated tumors are related to recurrence [58]. Clinic and histological features are important to determine treatment, prognostic factors and survival rates $[58,59]$. There is a TNM staging scheme, for OSCC and salivary gland tumors [60]. At the initial stages survival rates reach $80 \%$, while at more advanced stages they decrease to $21 \%$ [54].
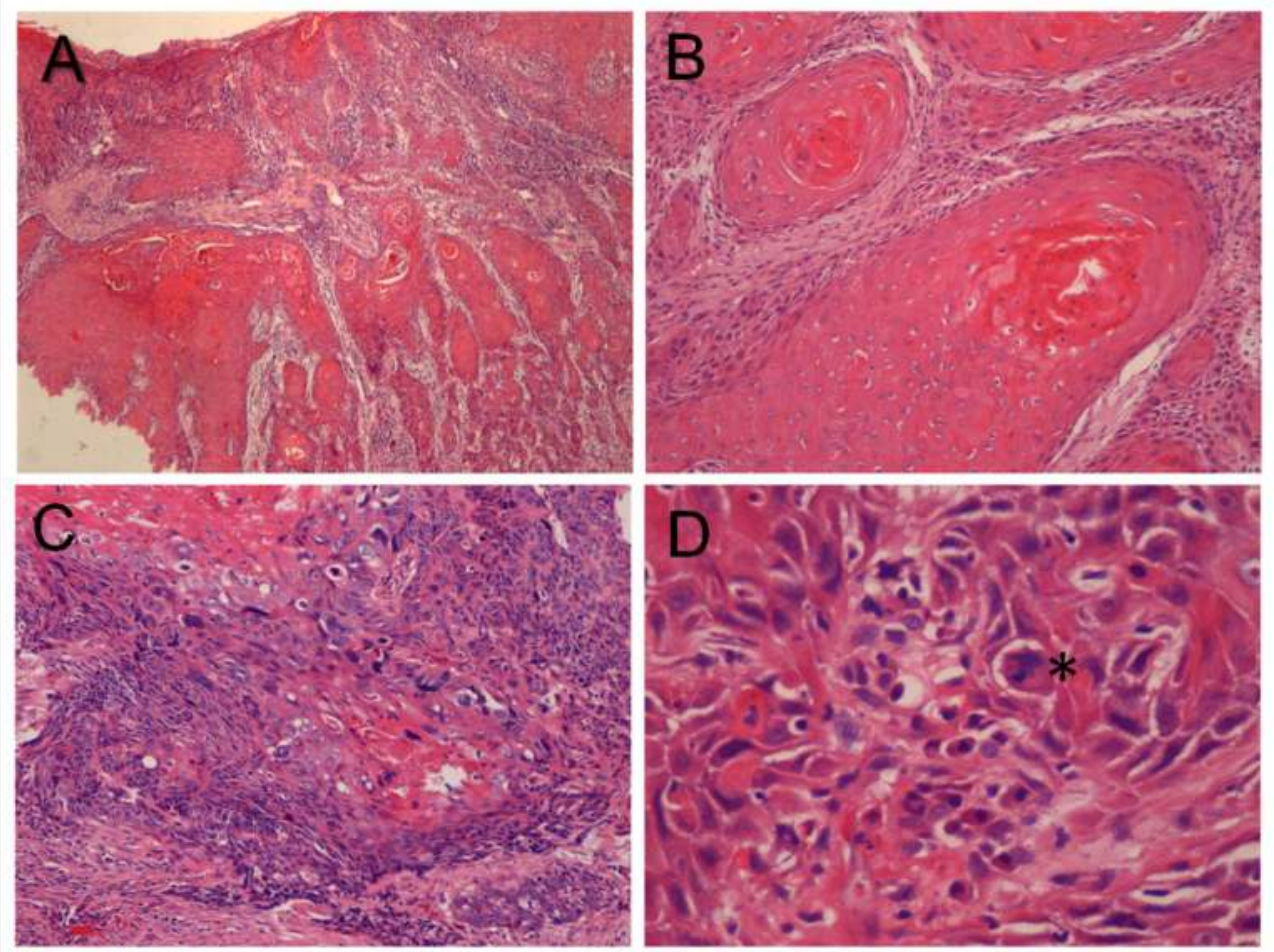

Figure 9. OSCC histopathology. It is possible to observe superficial non affected oral epithelia and tumoral islands in the stroma ( $\mathbf{A} ; \mathrm{HE}$, Objective $4 \mathrm{x})$. A closer view of the tumoral islands with central keratin (B; HE, Objective 10x). Pleomorphism and atypia are observed (C; HE, Objective 10x), as well as mitosis $\left(^{*}\right)$ and intercellular bridges (D; HE, Objective 20x).

A correlation between HPV and cervical SCC of the utherus has been identified, but despite the strong evidence of HPV presence, there is no clear-cut proof that would point to HPV as 
an isolate SCC cause on oral cavity. Some studies argue that HPV is a mere supporting causer $[1,61]$ while another study indicates that tumors positive for oncogenic types of HPV may show better survival [62], mainly in oropharynx, where HPV positive tumors are associated with a specific morphology (basaloid squamous cell carcinoma, a subtype of conventional carcinoma) and positivity for p16 using immunohistochemistry [63].

HPV-16 has been found in $90 \%$ of head and neck cancers and in $50 \%$ of oropharynx $[1,18,53$, 64]. However, some authors have not found such association [64].

Potentially malignant disorders such as leukoplakia, erytroplakia, proliferative verrucous leukoplakia and lichen planus may progress to OSCC [1] and upon biopsy, there may be already areas of an actual OSCC [65].

Surgical resection is the treatment of choice when the lesion is placed on oral cavity while chemoradiotherapy is used when the oropharynx is the afflicted site [22] or if it is a tumor in a very advanced stage [66].

Surgery may impair some functions as speech, swallowing, and chewing and abruptly change quality of life. To maintain swallowing and speech, an alternative course is ablative surgery (microvascular free tissue), but this is not regarded to be as effective as surgical resection. In advanced stage when metastasis is located on upper aerodigestive tract, treatment should be multimodal, combining surgery and chemoradiotherapy [46].

Recurrent OSCC is challenging as the risk of complication is increased due to fibrosis and tissue hipovascularization [51].

Radiotherapy may be primary, adjuvant or neoadjuvant. It is regarded as primary for unresectable tumor or for patients who cannot undergo surgery, adjuvant as a post-surgery complementary method, and neoadjuvant when performed before surgery to facilitate tumor resection [54].

\section{HPV oncogenic potential}

HPV infection may lead to cell immortalization by means of infection of the mucosa and skin basal epithelial cells, which are the only ones that keep in the cell cycle [8, 61]. It may be by itself a causative agent of malignant transformation or when associated with other unclear cofactors [61]. However, some researchers have argued that HPV is not able to cause malignant transformation, despite the studies which point to the contrary [12].

Some factors should come into play to immortalize cells: virus type, synergetic action among physics, biological and chemical agents and genetic constitution, which are able to modify the natural course of the disease. But if the exposed person has a favorable condition and acquires high risk HPV it becomes easier to integrate viral DNA into human genome [61].

Oral HPV has been diagnosed in OSCC and it is believed that it has been involved in oral carcinogenesis by transforming the keratinocytes through a mechanism involving E6 and E7 
proteins. However, the mechanisms behind immune response against high risk HPV remain unclear [67-69].

\section{HPV detection methods}

The identification of various types of HPV is a recent technological advance due to the growth impossibility in tissue cultures and research animals.

Diagnoses methods vary from simple to sophisticated ones, ranging from light microscopy to DNA expression, with low to high sensitivity. Light microscopy and in situ hybridization are considered low sensitivity methods because it only tests positive when there are more than 10 viral DNA copies per cell. Among the intermediate sensitivity methods we find southern blot, do blot and reverse hybridization with a positive detection result when there is from 1 to 10 DNA copies per cell. High sensitivity methods, such as PCR, needs less than 1 viral DNA copy per cell for microorganism detection [70].

\subsection{Light microscopy}

This method provides some data, even though it has low sensibility and it does not inform the HPV type. The most common HPV induced changes are epithelial thickening, prominent keratohyalin granules, hyperkeratosis, nuclear dysplasia, hyperchromasia, double nucleation of superficial and intermediated cell, perinuclear cytoplasmic halos, and atypical immature metaplasia [9].

\subsection{Electron microscopy}

HPV particles may be identified by electron microscopy (EM), but not the HPV type. EM can detect the presence of virion on koilocytic and dyskeratotic cell nuclei, but it is a limited method to investigate infection, because high risk HPV do not reproduce and as such cannot be identified through EM [5].

\subsection{Molecular methods}

Molecular methods can be divided into two types: non-hybridization, such as in situ amplification, southern and dot blot hybridization and the amplified, such as target amplification, signal amplification and probe amplification. Target amplification is best exemplified by PCR. Signal amplification may be represented by hybrid technique sample. Probe amplification which is a compound-probe is added to a probe generating signal (Ligase Chain Reaction) according to literature [5].

\subsection{In Situ Hybridization (ISH)}

In situ hybridization using biotinylated probes is a common method for detecting HPV in oral epithelium. It is practical and economical for screening for HPV in clinical pathology labora- 
tories. In situ hybridization also permits direct comparison of viral DNA location with histologic morphology $[9,71]$. Although this technique is highly sensitive in cases in which individual nuclei contain a high copy number of the target DNA, as is likely to occur in most active infections, the method of ISH often fails to detect cases in which subgenomic fragments of the viral DNA have been incorporated into the host genome and the infection is nonproductive of intact viral particles. So when there is low viral DNA amount, it leads to low sensitivity [71, 72]

\subsection{Southern blot and dot blot hybridization}

Southern Blot classifies and identifies new viral types. It is a labor-intensive process that requires well trained skills and depends on a new generation of equipments. This technique requires the total length of a DNA molecule, and offers additional information about viral integration and subtype [70].

Dot blot is a simplified southern blot, requiring less sophisticated facilities, but it is rarely performed because of its low sensitivity. It is often used as detection kits available on the market [70].

\subsection{Target amplification}

The classic example of target amplification is PCR. This is the best subtype detection method due to the high sensitivity [9]. It is commonly used as diagnostic tool for HPV DNA epidemiological investigation, but because of the high cost this method cannot be used in a routine clinical practice. PCR has a high sensitivity and it is very effective for both malignant and pre malignant lesions identification, and material can be collected with oral swab or wash $[7,9]$.

\subsection{Hybrid Capture technology (HC)}

Using signal amplification with microplate chemiluminescent detection, this method identifies nucleic acid due to its high sensitivity [9]. HC is a very important tool to detect high risk HPV, and the method has identified HPV 16, 18, 31, 33, 35, 39, 45, 51, 52, 56, 58, 59, 68 types [9]. This technique is able to identify 5000 viral copies per sample [73].

\subsection{Probe amplification}

Probe amplification methods differ from target amplification in that the amplification products contain a sequence only present in the initial probes. It is used currently as an important diagnostic application, the detection of high-risk genotypes of human papilloma viruses (HPV) [74].

\subsection{Education and vaccine prophylaxis}

One simple and effective prophylactic measure is patient education. It must be clear to patients that even after treatment the virus remains on the oral mucosa, so it is imperative to maintain good oral hygiene, condom use in all sexual relations and refrain from promiscuous sexual 
behavior. Clinical examinations have to be done periodically and smoking and chronic alcoholism must be abolished.

It is crucial that the population in general be informed about HPV prevention as a control strategy and early diagnosis promotion. Raising awareness of HPV through education is essential to develop population perception about risk factors, mainly those related to sexual activity[18]. It is also important to discourage early sexual initiation [69].

In view of the increasing figures of cervix cancer, the US Food and Drugs Administration (FDA) approved in 2006 a vaccine against HPV [75]. There is a bivalent vaccine that contains $\mathrm{L}_{1}$ HPV-16/18 protein which generates a huge number of genotype specific antibody [75]. For HPV 16/18 vaccine efficiency is round $96 \%$ on cervix cancer [69]. There is also a tetravalent vaccine that works in the same way as the bivalent, but provides further immunity enclosing HPV types 6, 11, 16, 18 [75]. Both of them use virus- like particles in their composition [9].

The vaccine(s) stimulates humoral response, but it also stimulates B cell immune memory response, which persists for five years [69]. After a 5 years follow up, it has demonstrated $100 \%$ of efficacy on persistent infection prevention [8].

As HPV's physiopathology is very similar on the affected sites, whether they are the skin, cervix, penile, anus or oral mucosa, there is no reason to doubt that the vaccine which works well on the cervix would also prove effective for the prevention of oral mucosa lesions [75].

As HPV-16 seems to be an important risk factor for the progress of malignant lesions (because it is found in most OSCCs), it might be possible that the vaccine would prevent or even treat them [8].

HPV vaccine seems to be less effective on women who have already been exposed to the virus, hence the public health focus on vaccinating girls before their first sexual relation to prevent warts and more disaster lesions in the future $[8,9]$. Some countries have promoted vaccination for any females from 9 to 26 years who have never had sexual experience before [76]. Other countries promote vaccination for females up to 45 years old [77]. Vaccines for men aged 11 up to 26 years old in order to prevent genital warts and anal cancer was approved in 2011 by the US Advisory Committee on Immunization Practices [78].

$\mathrm{HPV}$ is as frequent in men as in women; however, it is often asymptomatic in males, what makes them a HPV reservoir to cervix and non- cervical lesions in females, transmitted mainly by sexual activity [69]. Current studies have been done in order to further assess the natural history of the HPV infection in men $[79,80]$.

A therapeutic vaccine is under study, one which could be used as adjuvant on surgery or radiotherapy, to clean up microscopic waste of the lesion, thus generating immune response.

In view of the potential risks of HPV and the potential benefits of the vaccine (some not yet fully established) some researchers favor the extended use of the vaccine to all age groups of both sexes, regardless of previous sexual practice, as a form to interrupt the transmission cycle 
and as a preventive strategy in controlling and avoiding the risks posed by HPV, including various types of cancer in different locations in the human body.

\section{Acknowledgements}

We would like to thank Professor Simone Lourenço and Márcia Sother who were active in building clinical images archives for the Stomatology Specialization Course at Odontoclinica Central do Exército (OCEx - Rio de Janeiro, Brasil).

\section{Author details}

Helena Lucia Barroso dos Reis ${ }^{1,4}$, Silvia Paula de Oliveira ${ }^{2,3}$, Danielle Resende Camisasca ${ }^{1,4}$, Juliana Bittencourt Pessoa ${ }^{5}$, Ana Beatriz Azevedo Queiroz ${ }^{2}$, Mauro Romero Leal Passos ${ }^{4}$, Philippe Godefroy ${ }^{4}$, Dennis de Carvalho Ferreira ${ }^{2}$, Thais Camporez Pimentel ${ }^{5}$ and Antonio Chambo Filho ${ }^{5}$

1 Federal University of Espirito Santo, Brazil

2 Federal University of Rio de Janeiro, Brazil

3 Odontoclinica Central do Exercito of Rio de Janeiro, Brazil

4 Fluminense Federal University, Brazil

5 Santa Casa de Misericórdia School of Science, Brazil

\section{References}

[1] Feller L, Khammissa RAG, Wood NH et al. Epithelial maturation and molecular biology of oral HPV. Infect Agent Cancer 2009;4:16.

[2] Syrjänen S, Lodi G, von Bültzingslöwen I, Jontell M et al. Human papillomaviruses in oral carcinoma and oral potentially malignant disorders: a systematic review. Oral Dis 2011 Apr;17 Suppl 1:58-72.

[3] Durzynska J, Pacholska-Bogalska J, Kaczmarek M et al. HPV genotypes in the oral cavity/oropharynx of children and adolescents: cross-sectional survey in Poland. Eur J Pediatr 2011;170:757-61. 
[4] Ezquenazi D, Filho IB, Carvalho MGC et al. The frequency of human papillomavirus findings in normal oral mucosa of healthy people. Braz J Otorhinolaryngol 2010;76(1):78-84.

[5] Kumaraswamy KL, Vidhya M. Human Papilloma virus and oral infections: an update. J Cancer Res Ther 2011;7(2):120-7.

[6] Syrjänen, S. The role of human papillomavirus infection in head and neck cancers. Ann Oncol 2010;21(7) 243-5.

[7] Michl P, Pazdera J, Prochazka M et al. Human Papillomavirus in the etiology of head and neck carcinomas. Biomed Pap Med Fac Univ Palacky Olomouc Czech Repub 2010;154(1):9-12.

[8] Mannarini L, Kratochivil V, Calabrese L et al. Human Papilloma Virus (HPV) in head and neck region: review of literature. Acta Otorhinolaryngol Ital 2009;29:119-26.

[9] Chlaudhary AK, Singh M, Sundaram S et al. Role of human papillomavirus and its detection in potentially malignant and malignant head and neck lesions: updated review. Head Neck Oncol 2009;1:22.

[10] Castro TMPPG, Filho IB, Nascimento VX et al. HPV detection in the oral and genital mucosa of women with positive histopathological exam for genital HPV, by means of the PCR. Braz J Otorhinolaryngol 2009;75(2):167-71.

[11] Fakhry C, Sugar E, D'Souza G et al. Two-Week versus Six-Month Sampling Interval in a Short-Term Natural History Study of Oral HPV Infection in an HIV-Positive Cohort. PLoS One 2010;5(7):e11918.

[12] Panonne G, Santoro A, Papagerakis S et al. The role of human papillomavirus in the pathogenesis of head \& neck squamous cell carcinoma: an overview. Infect Agent Cancer 2011;6:4.

[13] Rombaldi RL, Serafini EP, Mandelli J et al. Transplacental transmission of Human Papillomavirus. Virol J 2008;5:106.

[14] Zwenger SR. Bogarting that joint might decrease oral HPV among cannabis users. Curr Oncol 2009;16(6):5-7.

[15] Castro TMPPG, Filho IB. Prevalence of human papillomavirus (HPV) in oral cavity and oropharynx. Braz J Otorhinolaryngol 2006;72(2):272-82.

[16] Sánches-Vargas LO, Díaz-Hernández C, Martinez-Martinez A. Detection of Human Papilloma Virus (HPV) in oral mucosa of women with cervical lesions and their relation to oral sex practices. Infect Agent Cancer 2010;4;5(1):25.

[17] Pereira CM, Melo LG, Correa MM et al. Oral HPV infection in a boné marrow transplantation patient: a case report with atypical clinical presentation and unexoected outcome. Braz J Infect Dis 2010;14(1):89-91. 
[18] Castro TMPPG; Neto CER, Scala KA et al. Oral manifestations related to papillomavirus. Braz J Otorhinolaryngol 2004;70(4):546-50.

[19] Rombaldi RL, Serafini EP, Mandelli J et al. Perinatal transmission of human papillomavirus DNA. Virol J 2009;6:83.

[20] Filho JAX, Simoceli L, Imamura R et al. Recurrent laryngeal papillomatosis: a 10-year experience. Braz J Otorhinolaryngol. 2003;69(5): 599-604.

[21] Rintala MAM, Grénman SE, Järvenkyla ME et al. High-risk types of humam papillomavirus (HPV) DNA in oral and genital mucosa of infants during their first 3 year of life: experience from the finnish HPV family study. Clin Infect Dis 2005;15;41(12): 1728-33.

[22] Reis HLB, Ferreira DC, Forattini AG, Souza PG, Curvelo JAR, Passos MRL. Genital and oral human papillomavirus infection in a patient from the group of women who have sex with women. Clinics 2010; 65(12): 1383-1385.

[23] Syrjänen K, Syrjänen S. HPV infection of the oral Mucose. Papillomavirus infections in human pathology. Chichester, England: John Wiley \& Sons Ltd, 2000:380.

[24] Scheurer ME, Tortolero-Luna G, Adler-Storthz K. Human papillomavirus infection: biology, epidemiology, and prevention. Int J Gynecol Cancer 2005; 15: 727-746.

[25] Anderson K M, Perez-Montiel D, Miles L et al. The histologic differentiation of oral condyloma acuminatum from its mimics. Oral Surg Oral Med Oral Pathol Oral Radiol Endod 2003; 96:420-8.

[26] Praetorius F. HPV-Associated diseases of oral mucosa. Clinics in Dermatology 1997;15:399-413.

[27] Jaju PP, Suvarna PV, Desai RS. Squamous papilloma: case report and review of literature. Int J Oral Sci 2010;2(4),222-5.

[28] Carneiro TE, Marinho SA, Verli, FD et al. Oral squamous papilloma: clinical, histologic and immunohistocheamecal analyses. J Oral Sci 2009;51(3):367-72.

[29] Bassioukas K, Danielides V, Georgiou I et al. Oral focal epithelial hyperplasia. Eur J of Dermat 2000;10(5):395-7.

[30] Vera-Iglesias E, García-Arpa M, Sanchéz-Caminero P et al. Focal epithelial hyperplasia. Actas Dermosifiliogr 2007;98(9):621-3.

[31] Hashemipour MA, Shoryabi A, Adhami S et al. Extensive Focal Epithelial Hyperplasia. Arch Iran Med 2010;13(1):48-52.

[32] Delgado Y, Torrelo A, Colmenero I et al. Hiplerplasia epitelial focal. Actas Dermosifiliogr 2005;96(10):697-9. 
[33] Fernández-González F, Vázquez-Ávarez R, Reboiras-López D et al. Histopathological findings in oral lichen planus and their correlation with the clinical manifestations. Med Oral Patol Oral Cir Bucal 2011;1;16(5):e641-6.

[34] Edwards PC, Kelsch R. Oral Lichen Planus: Clinical Presentation and Management. J Can Dent Assoc 2002;68(8):494-9.

[35] Nico MMS, Lourenço SM, Fernandes JD. Oral lichen planus. An Bras Dermatol 2011;86(4):633-43.

[36] van der Meij EH, van der Waal I. Lack of clinicopathologic correlation in the diagnosis of oral lichen planus based on the presently available diagnostic criteria and suggestions for modifications. J Oral Pathol Med 2003; Oct;32(9):507-12.

[37] van der Waal I. Potentially malignant disorders of the oral and oropharyngeal mucosa; terminology, classification and present concepts of management. Oral Oncol 2009; Apr-May;45(4-5):317-23.

[38] Martorell Calatayud A, Botella-Estrada R, Bagán-Sebastián et al. Oral Leukoplakia: Clinical, Histopathologic, and Molecular Features and Therapeutic Approach. Actas Dermosifiliogr 2009;100:669-84.

[39] Smitha T, Sharada P, Girish HC. A white patch or plaque that cannot be characterized clinically or histologically as any other disease. J Oral Maxillofac Pathol 2011;15(1):26-33.

[40] Kreuter A, Wieland U. Oral hairy leukoplakia: a clinical indicator of immunosuppression. CMAJ 2011;183(8):932.

[41] Sapna N, Vandana KL. Idiopathic linear leukoplakia of gingiva: a rare case report. J Indian Soc Periodontol 2010;14(3):198-200.

[42] Lodi G, Sardella A, Bez C, et al. Interventions for treating oral leukoplakia. Cochrane Database Syst Rev 2006; Oct 18;(4):CD001829.

[43] Alkan A, Bulut E, Gunhan O et al. Oral Verrucous Carcinoma: A Study of 12 Cases. Eur J Dent 2010;4(2):202-7.

[44] Santoro A, Pannone G, Contaldo M el al. A Troubling Diagnosis of Verrucous Squamous Cell Carcinoma ("the Bad Kind" of Keratosis) and the Need of Clinical and Pathological Correlations: A Review of the Literature with a Case Report. J Skin Cancer 2011;2011:370605.

[45] Barnes L, Eveson J.W., Reichert P., Sidransky D. World Health Organization Classification of Tumours. Pathology and Genetics of Head and Neck Tumours. Lyon: IARC Press; 2005.

[46] Kang CJ, Chang JT, Chen IH et al. Surgical Treatment of Oral Verrucous Carcinoma.Chang Gung Med J 2003;26(11):807-12. 
[47] Falaki F, Dalirsani Z, Pakfetrat A et al. Clinical and histopathological analysis of oral squamous cell carcinoma of young patients in Mashhad, Iran: a retrospective study and review of literature. Med Oral Patol Oral Cir Bucal 2011;16(4):e473-7.

[48] Fan S, Tang QL, Chen WL et al. A review of clinical and histological parameters associated with contralateral neck metastases in oral squamous cell carcinoma. Int J of Oral Sci 2011;3(4):180-191.

[49] Arkbulut N, Oztas B, Kursun S et al. Delayed diagnosis of oral squamous cell carcinoma: a case series. J Med Case Reports 2011;5(1):291.

[50] Friedrich RE, Sperber C, Jakel T, Roser K, Loning T. Basaloid lesions of oral squamous epithelial cells and their association with HPV infection and P16 expression. Anticancer Res 2010;30:1605-1612.

[51] Miller CS, Johnstone BM. Human papillomavirus as a risk factor for oral squamous cell carcinoma: a meta-analysis, 1982-1997. Oral Surg Oral Med Oral Pathol Oral Radiol Endod 2001; Jun 91(6):622-35.

[52] Warnakulasuriya S. Global epidemiology of oral and oropharyngeal cancer. Oral Oncol 2009;45(4-5):309-316.

[53] Termine N, Panzarella V, Falaschini S et al. HPV in oral squamous cell carcinoma vs head and neck squamous cell carcinoma biopsies: a meta-analysis. Ann Oncol 2008;19(10):1681-90.

[54] Kademani D. Oral Cancer. Mayo Clin Proc 2007;82(7):878-87.

[55] Cordella C, Lubbers HT, Rivelli V et al. An evaluation of the preoperative hemoglobin level as a prognostic factor for oral squamous cell carcinoma. Head Neck Oncol 2011;15;3:35.

[56] Dias FL, Kligerman J, Matos de Sa G, et al. Elective neck dissection versus observation in stage I squamous cell carcinomas of the tongue and floor of the mouth. Otolaryngol Head Neck Surg 2001;125(1):23-9.

[57] Kligerman J, Lima RA, Soares JR, et al. Supraomohyoid neck dissection in the treatment of T1/T2 squamous cell carcinoma of oral cavity. Am J Surg 1994;168(5):391-4.

[58] Camisasca DR, Silami MA, Honorato J, Dias FL, de Faria PA, Lourenco SQC. Oral squamous cell carcinoma: clinicopathological features in patients with and without recurrence. ORL J Otorhinolaryngol Relat Spec 2011;73(3):170-6.

[59] Camisasca DR, Honorato J, Bernardo V, et al. Expression of Bcl-2 family proteins and associated clinicopathologic factors predict survival outcome in patients with oral squamous cell carcinoma. Oral Oncol 2009;45(3):225-33.

[60] Nguyen NP, Chi A, Nguyen LM et al. Human papillomavirus-associated oropharyngeal cancer: a new clinic entity. QJM 2010;103(4):229-36. 
[61] Ritchie JM, Smith EM, Summersgill KF, Hoffman HT, Wang D, Klussmann JP, Turek LP, Haugen TH. Human papillomavirus infection as a prognostic factor in carcinomas of the oral cavity and oropharynx. Int J Cancer 2003; 104(3): 336-44.

[62] Syrjanen S. Human papillomaviruses in head and neck carcinomas. N Engl J Med 2007;356(19):1993-5.

[63] Ha PK, Pai SI, Westra WH et al. Real-time quantitative PCR demonstrates low prevalence of human papillomavirustype 16 in premalignant and malignant lesions of the oral cavity. Clin Cancer Res 2002; 8(5):1203-9.

[64] Warnakulasuriya S, Johnson NW, van der Waal I. Nomenclature and classification of potentially malignant disorders of the oral mucosa. J Oral Pathol Med 2007;36(10): $575-80$.

[65] Hassel AJ, Danner D, Freier K et al. Oral health-related quality of life and depression/ anxiety in long-term recurrence-free patients after treatment for advanced oral squamous cell cancer. J Craniomaxillofac Surg 2012;40(4):e99-102.

[66] Ji X, Neumann AS, Sturgis EM et al. p53 codon 72 polymorphism associated with risk of human papillomavirus-associated squamous cell carcinoma of the oropharynx in never smokers. Carcinogenesis 2008;29(4):875-9.

[67] Westra, W.H. The changing face of head and neck cancer in the 21st century: the impact of HPV on the epidemiology and pathology of oral cancer. Head Neck Pathol 2009;3(1):78-81.

[68] Feller F, Wood NH, Khammissa RA et al. Human papillomavirus-mediated carcinogenesis and HPV-associated oral and oropharyngeal squamous cell carcinoma. Part 2:Human papillomavirus associated oral and orapharyngeal squamous cell carcinoma. Head Face Med 2010;6:15.

[69] Oliveira MC, Soares RC, Pinto LP et al. HPV and oral carcinogenesis: a bibliographic review. Braz J Otorhinolaryngol 2003;69(4):553-9.

[70] Shroyer KR, Greer Jr RO. Detection of human papillomavirus DNA by in situ hybridization and polymerase chain reaction in premalignant and malignant oral lesions. Oral Surg Oral Med Oral Pathol 1991;71:708-13.

[71] Coutlee F, Danielle R, Alex F, Eduardo F. The laboratory diagnosis of genital humanpapilloma virus infections. Can J Infect Dis Med Microbiol 2005;16:83-91.

[72] Tang WK. Oncogenic human papillomavirus infection: Epidemiology in local highrisk women. Hong Kong Dermatol Venereol Bull 2002;10:160-63.

[73] Ginocchio CC, Barth D, Zhang F. Comparison of the Third Wave Invader human papillomavirus assay and the Digene HPV hybrid capture assay for detection of high-risk HPV. J Clin Microbiol 2008; 46:1641-1646. 
[74] Gillson ML, Chaturvedi AK, Lowy DL. HPV prophylactic vaccines and potential prevention of noncervical cancers in both men and women. Cancer 2008;15;113(10): 3036-46.

[75] Einstein $\mathrm{MH}$, Baron M, Levin MJ,et al. Comparative immunogenicity and safety of human papillomavirus (HPV)-16/18 vaccine and HPV-6/11/16/18 vaccine: follow-up from months 12-24 in a Phase III randomized study of healthy women aged 18-45 years. Hum Vaccin 2011; 7: 1343-1358.

[76] Centers for Disease Control and Prevention. Recommendations on the use of quadrivalent human papillomavirus vaccine in males-Advisory Committee on Immunization Practices (ACIP), 2011. http://www.cdc.gov/mmwr/preview/mmwrhtml/ mm6050a3.htm (accessed 26 Jul 2013).

[77] Daron GF, Waller JL, Miller J et al. Variables associated with human papillomavirus (HPV) vaccine acceptance by men. J Am Board Fam Med 2009; 22 (1):34-42.

[78] Kreimer AR, Pierce Campbell CM, Lin HY et al. Incidence and clearance of oral human papillomavirus infection in men: the HIM cohort study. Lancet 2013; Sep 7;382(9895):877-87.

[79] Kreimer AR, Villa A, Nyitray AG et al. The epidemiology of oral HPV infection among a multinational sample of healthy men. Cancer Epidemiol Biomarkers Prev 2011; Jan;20(1):172-82. 